\title{
Met and unmet needs of children with epilepsy in a paediatric tertiary care setting
}

\author{
H Perera ${ }^{1}$ and GDI Rodrigo ${ }^{2}$
}

\begin{abstract}
Objective To investigate the extent to which the health needs were met or unmet in children with epilepsy attending a tertiary care outpatient setting.

Patients and method A semi-structured interview was used to collect relevant information from the parents. It focused on ascertaining the quality of health care received by the children, including the extent to which attention was given to epilepsy related physical, behavioural, social and educational impairments that were identified by the parents.
\end{abstract}

Results There was satisfactory seizure control in the majority. Most children received only one anticonvulsant and side-effects were reported to be minimal. A large majority had behavioural problems, and social and educational difficulties to a lesser extent. Parents were concerned about the implications of these problems, but there was little communication about them in the doctorpatient contact. Even where the problems were communicated, parent satisfaction about the interventions was low. Parents identified the availability of more consultation time and provision of more information on epilepsy as their expectations from doctors.

Conclusions This study shows that awareness and communication about the multiple health problems of children with epilepsy are necessary to improve the quality of health care given to them.

\section{Introduction}

Children with epilepsy commonly suffer from multiple impairments and disabilities, including emotional, behavioural, social, cognitive and educational difficulties [1-3]. In addition, the impact of social stigma are negative experiences for them $[4,5]$. When compared to other chronic illnesses, prevalence of such problems is higher with epilepsy [6]. However, management of epilepsy traditionally focuses on seizure control, whereas other related health problems receive minimal attention. In investigations into the quality of care in epilepsy using patient feedback, the medical profession is criticised for being unhelpful, and not adequately meeting their health needs [7]. By definition, health needs are considered unmet if relevant interventions are not made or are unavailable [8]. Similarly, met health needs minimise impairments and disability through recognition, and optimum treatment and care. Comprehensive care that effectively manages education and restrictions to life improves outcome in children with epilepsy [9-11]. In providing such care, it is important to take into account the needs expressed by the patient and family and their satisfaction with outcome of treatment $[18,12]$.

The broad objective of this study was to investigate the extent to which the health needs were met or unmet in children with epilepsy receiving outpatient care. The specific objectives were to explore (i) positive aspects of care, (ii) impairments and disabilities identified by the parents, and (iii) the extent to which communication occurred about them in the doctor-patient contact.

\section{Method}

The sample was chosen from children attending specialist paediatric outpatient clinics at the Lady Ridgeway Hospital for children in Colombo. At a given clinic, all the children who were taking treatment for epilepsy for 12 months or more were included in the study. Nine such clinics conducted by three specialist units were used for the study. Children who were on treatment for other concurrent long term illnesses were excluded.

The parent accompanying the child was interviewed for 15 to 20 minutes. This was a semi-structured interview which focused on (i) demographic data of the child, (ii) distance from residence to the hospital, (iv) educational attainment of the parent, and (v) different aspects of care under the following topics.

\section{Information on drug treatment of epilepsy}

This aspect of enquiry concentrated on (i) medication and its adverse effects, and (ii) level of seizure control. A

${ }^{1}$ Senior Lecturer, Department of Psychological Medicine and ${ }^{2}$ Senior Lecturer, Department of Paediatrics, Faculty of Medicine, Kynsey Road, Colombo 8, Sri Lanka.

Correspondence: HP, Tel: +94 11 2856361, e-mail: hemamali_p@yahoo.com (Competing interests: none declared). 
checklist of common side-effects of anticonvulsants was offered to the parent to identify those affecting the child.

\section{Parents' knowledge about epilepsy}

The aim was to ascertain whether the parent had accurate knowledge about the cause of epilepsy, action of the drugs and first aid in the event of a seizure at home. If the source of this knowledge was the doctor, the parents were asked whether the information had to be requested or was volunteered.

\section{Behaviour, social or educational problems in the child}

The parents were asked (i) whether the child had problems in each of these aspects of functioning and to identify the type of problem from the checklist, (ii) whether the presence of the problems was communicated to the doctor, and if so, (iii) the intervention offered and its effectiveness. The checklists on behavioural, social and educational problems were constructed from published data on children with epilepsy and other chronic illnesses [2, 13].

\section{Other expectations}

The parents were asked to state whether they were satisfied with the (i) amount of information received on the child's illness, (ii) consultation time with the doctor, and (iii) the attitude of the doctor. They were also asked whether financial assistance was expected from the hospital.

\section{Statistical analysis}

The data was analysed using EPI version 6 (WHO) to calculate the frequency of occurrence of the variables studied and the association between them.

\section{Results}

The sample included 77 children aged from 2 to 13 years (mean 6.2, SD 3.5). Males were 57.1\%. The duration of epilepsy in the sample was 1 to 11 years (mean 3.3, SD 2.66). The mean duration of treatment was 3.1 years. Information regarding the educational attainment of parent and the distance travelled to attend the clinic are given in Table 1.

Table 2 gives information on seizure frequency and medication. Parents were satisfied with the level of seizure control in $48.1 \%$ cases, moderately satisfied in $29.9 \%$ cases and dissatisfied in $22.1 \%$.

All the children were taking anticonvulsant medication. Table 2 gives the frequency of side-effects of medication. Drowsiness was the commonest (32.5\%). Restlessness was reported by $18.2 \%$, but in some, the cause may be behavioural rather than medication.

In $64.9 \%$ sufficient and accurate knowledge was displayed by parents on the cause of epilepsy, and in $26 \%$ on the action of anticonvulsant drugs. In $62.3 \%$, parents could not name even one drug given to the child. In $63.6 \%$, parents showed sufficient knowledge of first aid in the event of a seizure at home. In $81.8 \%$, doctors were the main source of information about epilepsy, but $65.2 \%$ of this group felt that information was provided only on request.

Table 1. Information related to parent who responded to the interview

\begin{tabular}{lcc}
\hline & $n$ & $\%$ \\
\hline Educational attainment & 32 & 41.6 \\
Primary school & 41 & 53.7 \\
Secondary school & 1 & 1.3 \\
Tertiary education & 3 & 3.9 \\
Never attended school & & \\
Distance travelled to attend clinic & 33 & 42.9 \\
Less than $10 \mathrm{~km}$ & 20 & 26 \\
10 to $30 \mathrm{~km}$ & 24 & 31.2 \\
\hline
\end{tabular}

Table 2. Epilepsy related information about the child

n $\%$

\section{Seizure frequency}

One episode per week

One episode per month

None in 3 months

None in 6 months

None in one year or more

\section{Anticonvulsants}

Taking drugs

Taking one drug

Taking two drugs

Taking $>2$ drugs

\section{Side-effects of medication}

Side-effects experienced

Mild

Moderate to severe

In $87.9 \%$ of children, parents identified one or more behavioural problems (mean 1.8, SD 1.34, SE 0.15). Lack of co-operation $(24.7 \%)$, temper tantrums $(22.1 \%)$ and aggressive behaviour $(19.5 \%)$ were common; $10.4 \%$ of children were recognised as overactive. 
Social problems were identified by parents in $61 \%$ of children (mean 1.3, SD 1.4, SE 0.15). Shyness (26\%), low confidence $(16.9 \%)$, reluctance to mix with other children $(10.4 \%)$ were common. $46.8 \%$ of children were identified to have school related problems (mean 0.98, SD 1.25, SE 0.14), 18.2\% had low achievement and $14.3 \%$ were reluctant to go to school. A further $9.1 \%$ were thought to be poorly motivated to learn.

Parents admitted that they did not complain to the doctor about the child's behavioural problems in $41.4 \%$ of cases, social problems in $66.1 \%$ and educational problems in $36.1 \%$. However they were concerned and wanted help for these problems. Parents perceived the interventions offered by the doctor for behavioural problems as very useful in $5.9 \%$ of children, and somewhat useful in $19.2 \%$ of children. The figures for social problems were $4.2 \%$ and $10.6 \%$ respectively and for school related problems, $8.3 \%$ and $19.4 \%$ respectively.

In $71.4 \%$, parents expected more epilepsy related information directly from the medical staff. In $13 \%$ assistance was expected in obtaining financial help in meeting the costs of the child's illness. In $19.5 \%$, parents expressed dissatisfaction with the amount of medical consultation time of clinic visits and $6.5 \%$ thought the doctors were insensitive to their problems.

\section{Discussion}

Some published practice guidelines for epilepsy recommend focusing on biological, psychological and social needs of the patient [14]. Taking such guidelines and known impairments and disabilities into account, this study identifies several health needs that were met and unmet in epileptic children. On the positive side, over half the children $(53.3 \%)$ had a reasonably good control of seizures, though parent satisfaction is marginally lower at $48 \%$. In nearly $75 \%$ of the children, only one anticonvulsant was prescribed to control the seizures. The prevalence of side-effects was also low with over $85 \%$ either not reporting any or only mildly affected by them. In addition, a majority of the parents $(64.9 \%)$ displayed sufficient knowledge about the cause of epilepsy and a similar number had accurate knowledge about management of a seizure at home. This level of knowledge matched the education of parents; a majority $(55 \%)$ had received secondary school education. Another positive aspect was that doctors had played a major role in providing information and education about epilepsy, though the majority of parents felt that they had to ask for it.

The aspects where the health needs of these children were largely unmet were with regard to behavioural, social and educational difficulties. It is a known fact that patients and parents are reluctant to voice psychosocial needs to doctors but this may lead to dissatisfaction about care and poor compliance $[15,16]$. In our study too, these burdensome difficulties were not reported by a majority of parents. At the same time, in the presence of a large number of unmet needs, the demand for better delivery of illness related information by patients and families is known to be high $[5,17,18]$. In our study the request for more information by parents of nearly $75 \%$ children, and dissatisfaction about consultation time with the doctor by nearly $20 \%$, point to a high level of unmet needs.

A relatively small number (13\%) expected financial assistance towards supporting the child's management. Over $30 \%$ of the patients travelled over $30 \mathrm{~km}$ to get treatment.

The small sample and the setting do not allow the results to be generalised. Absence of data on family background is a shortcoming and limits analysis and interpretation of parent responses to the interview. However, the study highlights shortcomings in the services for children with epilepsy. Such shortcomings even in a tertiary care paediatric setting where resources are better than elsewhere in the country is unfortunate in terms of quality of care offered to children with epilepsy.

\section{References}

1. Ott D, Caplan R, Guthrie D, Siddarth P, Komo S, et al. Measures of psychopathology in children with complex partial seizures and primary generalized epilepsy with absence. Journal of the American Academy of Child and Adolescent Psychiatry 2001; 40: 907-14.

2. Faewell J, Batzel L. Neuropsychological abilities in children with epilepsy. Epilepsia 1985; 26: 395-400.

3. Stanicolo M, Galleti F. Idiopathic epilepsy and school achievement. Archives of Diseases of Childhood 1994; 70: $424-8$

4. Carlton-Ford S, Miller R, Nealeigh N, Sanchez N. The effects of perceived stigma and psychological over-control on the behavioural problems of children with epilepsy. Seizure 1997; 6: 383-91.

5. Wiebe S, Bellhouse DR, Fallahay C, Eliasziw M. Burden of epilepsy: the Ontario Health Survey. Canadian Journal of Neurological Sciences 1999; 26: 263-70.

6. Houston EC, Cunningham CC, Metcalfe E, Newton R. The information needs and understanding of 5-10 year old children with epilepsy, asthma or diabetes. Seizure 2000; 9: 340-3.

7. Robinson RO, Edwards M, Madigan C, Ledgar S, Boutros A. Audit of a children's epilepsy clinic. Developmental Medicine and Child Neurology 2000; 42: 387-91.

8. World Health Organisation. International Classification of Impairments, Disabilities and Handicaps. Geneva: WHO, 1980.

9. Tettenborn B, Kramer G. Total patient care in epilepsy. Epilepsia 1992; (Suppl. 1) 33: S 28-32.

10. Garwick AW, Kohrman C, Wolman C, Blum RW. Families' recommendation for improving services for children with chronic conditions. Archives of Pediatrics and Adolescent Medicine 1998; 152: 440-8. 


\section{Papers}

11. Jessop DJ, Stein RE. Providing comprehensive healthcare to children with chronic illness. Pediatrics 1994; 93: 602-7.

12. Zeigler RG, Erba G, Holden I, Dennison H. The coordinated psychosocial and neurologic care of children with seizures and their families. Epilepsia 2000; 41: 732-43.

13. Stawski M, Auerbach JG, Barasch M, Lerner Y, Zimin R. Behavioural problems of children with chronic physical illness and their siblings. European Child Adolescent Psychiatry 1997; 6: 20-5.

14. Brown S, Betts T, Crawford P, Hall B, Shorvon S, Wallace S. Epilepsy needs revisited: a revised epilepsy needs document for the UK. Seizure 1998: 7: 435-46.

15. Barry CA, Bradley CP, Britten N, Stevenson FA, Barber N. Patients' unvoiced agendas in general practice consultations: qualitative study. British Medical Journal 2000; 320: 1246-50.

16. Cassidy LJ, Jellinek MS. Approaches to recognition and management of childhood psychiatric disorders in pediatric primary care. Pediatric Clinics of North America 1998; 45: 1037-52.

17. Laine C, Davidoff F, Lewis CE, Nelson EC, Nelson E, et al. Important elements of outpatient care: a comparison of patients' and physicians' opinions. Annals of Internal Medicine 1996; 125: 640-5.

18. Kwong KI, Wong SN, So KT. Parental perception, worries and needs in children with epilepsy. Acta Paediatrica 2000; 89: 593-6. 